\title{
RESPONSABILIDADE CIVIL SUBJETIVA DO CIRURGIÃO PLÁSTICO EM FACE DO DIREITO DA PERSONALIDADE DO PACIENTE
}

HORÁCIO MONTESCHIO

Pos doutorando na Universidade de Coimbra - Portugal e pelo UNICURITIBA, Paraná - Brasil. Doutor em Direito pela Faculdade Autônoma de São Paulo- FADISP. Mestre em Direitos da Personalidade - UNICESUMAR. Professor de Direito Administrativo Administrativo e Processo Administrativo do UNICURITIBA. Pós graduado em Direito Imobiliário e Direito processual civil pela Escola Paulista de Direito. Especialista em Processo Civil e Direito Público, pelo Instituto Brasileiro de Estudos Jurídicos, Direito Tributário, pela UFSC; em Direito Administrativo, pelo Instituto Romeu Felipe Bacellar; Direito Aplicado pela Escola da Magistratura do Estado do Paraná. Advogado, exSecretário de Estado da Indústria e Comercio e Assuntos do Mercosul do Estado do Paraná, ex-Secretário Municipal para Assuntos Metropolitanos de Curitiba; Integrante do Instituto dos Advogado do Paraná (IAP). Membro fundador e integrante do Instituto Paranaense de Advogados Eleitoralistas. Integrante das comissões de Direito Eleitoral e de Assuntos Legislativos da OAB/PR. ex-conselheiro do SEBRAE. ex-Presidente do Conselho da Junta Comercial do Estado do Paraná. Membro do Conselho Editorial do Instituto Paranaense de Direito Eleitoral.

\section{CLAYTON REIS}

Doutor em Direito pela Universidade Federal do Paraná (1999). Mestre em Direito pela Universidade Federal do Paraná (1996). Bacharel em Direito pela Faculdade de Direito de Curitiba (1970). Magistrado em Segundo Grau, aposentado, do TJPR. Professor na Escola da Magistratura do Paraná e pertence ao Corpo Docente Permanente do Programa de Mestrado em Direito Empresarial e Cidadania do UNICURITIBA. Realizou estágio Pós-doutoral na Faculdade de Direito da Universidade de Lisboa-Portugal (2013). Tem experiência em: Direito Civil: Responsabilidade Civil, Dano Moral. Direitos da Personalidade e Cidadania. 
Personalidade Acadêmica Homenageada:

Carlos Aurélio Mota de Souza (Universidade Ibirapuera - UNIB)

\section{GUSTAVO AFONSO MARTINS}

Mestre em Direito Empresarial e Cidadania pelo Centro Universitário Curitiba UNICURITIBA. Curso em Direito Internacional Público e Direitos Humanos organizado pelo lus Gentium Conimbrigae - Centro de Direitos Humanos. Universidade de Coimbra-Pt. Advogado desde 2012. Pós Graduação pela Ematra Escola da Magistratura do Trabalho - 9a Região (2014); Pós Graduação pela Faculdade Integrada do Brasil - Unibrasil (2012) em Direito Público; Possui graduação em Direito pela Faculdade Dom Bosco - Campus Marumby (2011). E-mail: gustavoamartins.cwb@gmail.com

\section{RESUMO}

O presente trabalho tem como objetivo principal analisar a responsabilidade civil do profissional médico, nas cirurgias plásticas estéticas, passando a investigar sua opção pela responsabilização firmada pela teoria do risco ou pela culpa, bem como, a produção probatória e a sua oportunidade de indenização. O Superior Tribunal de Justiça firmou corrente jurisprudencial em que consagra a obrigação de resultado e a aplicação da responsabilidade objetiva nos procedimentos estéticos, a qual faz ressonância com a maioria da doutrina pátria. Em sentido diametralmente oposto, apresenta-se tese fundada no fato de que se esse tipo de procedimento médico estético for visto sob o foco da responsabilidade subjetiva, abre-se uma seara de dilação probatória, que afasta a presunção objetiva presente nas decisões pretorianas. Por seu turno, as causas de exclusão da responsabilidade do médico nas cirurgias estéticas, e as consequentes imprevisibilidades destes procedimentos, demonstram que a adoção da responsabilidade subjetiva é a mais compatível com a realidade dessas intervenções. Ao analisar e justificar o entendimento do que vem a ser compreendido como obrigação de meio e obrigação de resultado, o trabalho possibilita, além do debate acadêmico, o objetivo em ofertar uma releitura sobre responsabilidade civil do médico nos procedimentos de natureza estética. As intervenções cirúrgicas estéticas podem prever com alto grau de probabilidade o resultado pretendido pelo profissional e pelo paciente. Todavia, predomina a 


\section{Personalidade Acadêmica Homenageada:}

Carlos Aurélio Mota de Souza (Universidade Ibirapuera - UNIB)

subjetividade e a imponderabilidade nestes procedimentos, em razão da imprevisibilidade dos resultados finais presentes nas cirurgias estéticas. Desta forma, vivenciamos um paradoxo fático assim inserido: de um lado a questão médica com afirmação de previsão do profissional no resultado do procedimento cirúrgico, alicerçada na responsabilidade objetiva. De outra banda, está o procedimento médico classificado como uma obrigação de meio devendo, em caso de insucesso, ser apurada a responsabilidade de forma subjetiva mediante a prova da culpabilidade do profissional médico. Nesse sentido, pretende-se estabelecer um liame entre a responsabilidade de meio do médico cirurgião estético a sua responsabilidade subjetiva, proporcionando a possibilidade de dilação probatória para as partes envolvidas em caso de insucesso nessa modalidade de cirurgia plástica.

PALAVRA-CHAVE: Responsabilidade objetiva e subjetiva do cirurgião plástico; responsabilidade de meio e responsabilidade objetiva envolvendo as cirurgias plásticas; dano estético.

\section{CONSIDERAÇÕES}

O presente trabalho teve como objetivo analisar criticamente 0 instituto da responsabilidade civil em face da atividade do profissional médico cirurgião plástico.

Consoante descrito no texto iniciou-se com uma breve análise histórica do médico, e desenvolvimento das técnicas cirúrgicas desenvolvidas por estes profissionais liberais.

Posteriormente, analisamos as questões relacionadas com a responsabilidade objetiva e subjetiva nos procedimentos médicos, na qual restou demonstrado a pertinência dessas modalidades de culpa, cotejando com referências doutrinárias e jurisprudenciais do Superior Tribunal de Justiça. Nessa mesma linha de reflexão, investigamos e constatamos a circunstância de que em todos os procedimentos cirúrgicos ocorre a existência da imponderabilidade, bem como, de diversos aspectos que ultrapassam os conhecimentos dos profissionais médicos. 
Personalidade Acadêmica Homenageada:

Carlos Aurélio Mota de Souza (Universidade Ibirapuera - UNIB)

Na sequência, investigamos igualmente a questão relacionada à obrigação de meio e de resultado do médico, oportunidade em que essa questão foi objeto de estudos e comentários. Observamos assistir razão a tese de que se trata de um procedimento de resultado. Todavia, não obstante a conclusão, constatamos de que a imprecisão, a subjetividade e a imponderabilidade constituem marcas notórias diante dos procedimentos médicos de natureza cirúrgica.

O dano estético é perfeitamente delimitável e aferível, sendo atribuída responsabilidade ao cirurgião no caso de lesão, competindo ao médico reparar os prejuízos, bem como, informar os riscos a que estão sujeitos os pacientes.

Por derradeiro, cabe salientar a proteção dos direitos da personalidade, bem como, as violações dos seus direitos Constitucionais, servindo-se as vítimas das lesões culposas, as indenizações em face dos textos constitucionais e do Código Civil. Ocorrendo danos ao patrimônio da vítima deverá o julgador delimitar a extensão do dano, bem como, fixar o valor do quantum indenizatório.

\section{REFERÊNCIAS}

AVELAR, Juarez Morares. Cirurgia plástica: obrigação de meio. São Paulo : Editora Hipocrates, 2000.

BITTAR, Carlos Alberto. Os direitos da personalidade. Rio de Janeiro : Forense Universitária, 1989.

BOUZON, Emanuel. O código de Hammurabi. Petrópolis : Vozes, 1987.

CAHALI, Yussef Said. Responsabilidade civil. São Paulo : Saraiva, 1988.

Dano moral. São Paulo: Editora Revista dos Tribunais, 1999.

CANTALI, Fernanda Borghetti. Direitos da personalidade : disponibilidade relativa, autonomia privada e dignidade humana. Porto Alegre : Livraria do Advogado Editora, 2009.

CASILO, João. Dano à pessoa e sua indenização. São Paulo ; Editora Revista dos Tribunais, 1987. 
Personalidade Acadêmica Homenageada:

Carlos Aurélio Mota de Souza (Universidade Ibirapuera - UNIB)

CAVALIERI, Sergio. Programa de responsabilidade civil. São Paulo : Editora Malheiros, 2003.

CHAVES, Antonio. Tratado de direito civil. São Paulo : Editora Revista dos Tribunais, 1982-1985.

DINIZ, Maria Helena. Curso de direito civil brasileiro. São Paulo : Saraiva, 2001.

FABIAN, Christoph. O dever de informar no direito civil. São Paulo : Editora Revista dos Tribunais, 2002. p. 137-138.

FERRAZ, Octávio Luiz Motta. Responsabilidade civil da atividade médica no código de defesa do consumidor. Rio de Janeiro : Elsevier, 2009.

FRANÇA, Genival Veloso de. Direito médico. São Paulo : Fundação BYK, 2003.

GAGLIANO, Pablo Stolze e PAMPLONA FILHO, Rodolfo. Novo curso de direito civil. São Paulo Saraiva, 2011.

GIOSTRI, Hildegard Taggesell. Erro Médico à luz da jurisprudência comentada, Curitiba: Juruá, 1998.

GONÇALVES, Carlos Roberto. Direito civil brasileiro. São Paulo : Saraiva, 2011.

KFOURI NETO, Miguel. Responsabilidade civil dos hospitais : código civil e de defesa do consumidor. São Paulo : Editora Revista dos Tribunais, 2010.

Tribunais, 2013.

Responsabilidade civil do médico. São Paulo : Editora Revista dos

LOPES, Teresa Ancona. O dano estético : responsabilidade civil. São Paulo: Editora Revista dos Tribunais, 2004.

MALUF, Adriana Caldas do Rego Freitas Dabus. Curso de bioética e biodireito. São Paulo : Atlas, 2013.

MELO, Nehemias Domingos de, Responsabilidade civil por erro médico : doutrina e jurisprudência. São Paulo : Atlas, 2013.

NADER, Paulo. Curso de direito civil. Rio de Janeiro : Forense, 2009.

OLIVEIRA, João Baptista de. Aspectos médicos-legais da anestesia. São Paulo : DGSB São Camilo, 1962.

OLIVEIRA, Mariana Massara Rodrigues de. Responsabilidade civil dos médicos. Curitiba : Juruá, 2008. 
Personalidade Acadêmica Homenageada:

Carlos Aurélio Mota de Souza (Universidade Ibirapuera - UNIB)

PANASCO, Wanderby Lacerda. A responsabilidade civil, penal e ética dos médicos. Rio de Janeiro : Forense, 1984.

PATARO, Oswaldo, in: Enciclopédia Saraiva do Direito. Coordenação do Professor R. Limongi de França. São Paulo : Saraiva . 1977, v. 14.

PEREIRA, Caio Mário da Silva. Responsabilidade civil. Rio de Janeiro : Forense, 1997.

POLICASTRO, Décio. Erro médico e suas conseqüências jurídicas. Belo Horizonte : Del Rey, 2013.

RASSAT, Michéle-Laure. La responsabilité civile. Paris : Presses Universitaires de France, 1973.

RÉ, Aluísio lunes Monti Ruggeri. A responsabilidade civil como sistema aberto : a abordagem constitucional do tema. São Paulo : Lemos e Cruz, 2007.

REIS, Clayton. Dano Moral. Rio de Janeiro : Forense, 1998.

Avaliação do dano moral. Rio de Janeiro : Forense, 1998.

RIZZARDO, Arnaldo. Responsabilidade civil. Rio de Janeiro : Forense, 2013.

RIPERT, Georges. A regra moral nas obrigações. Campinas : Bookseller, 2002.

ROMANELLO NETO, Jerônimo. Responsabilidade civil dos médicos. São Paulo : Editora Jurídica brasileira, 1998.

SANTOS, Alexandre Martins dos. Responsabilidade civil do médico. Rio de Janeiro : Editora DOC, 2011.

SCHAEFER, Fernanda. Responsabilidade civil do médico \& erro de diagnostico. Curitiba : Juruá, 2012.

SOUZA, Neri Tadeu Camara. Responsabilidade Civil e penal do médico. Campinas : LZN Editora, 2003.

STOCO, Rui. Tratado de responsabilidade civil. São Paulo : Editora Revista dos Tribunais, 2013.

VENOSA, Sílvio de Salvo. Direito civil: responsabilidade civil. São Paulo : Altas, 2005. 
Personalidade Acadêmica Homenageada:

Carlos Aurélio Mota de Souza (Universidade Ibirapuera - UNIB)

VIEIRA. Patrícia Ribeiro Serra. A responsabilidade civil objetiva no direito de danos. Rio de Janeiro : Forense, 2004. 